\title{
Age of onset in musical practice on cognitive functioning
}

\author{
Edad de inicio en la práctica musical en el funcionamiento cognitivo
}

Areta Ortega-Orozco ${ }^{a}$, Gabriela Orozco-Calderón ${ }^{b}$, Maura J. Ramírez-Flores ${ }^{c} \&$ Azucena Lozano- Gutiérrez ${ }^{d}$

\begin{abstract}
:
Musical processing has been described as a structural and functional plasticity model in which the areas involved and the connections are modified. These changes depend on several variables, including the start of training. The study of music as a neuropsychological phenomenon has become relevant because it provides information about possible cognitive benefits. Objective: Describe and compare how musical practice affects cognitive functioning in musicians who began their training at an early and late age. Method: Three groups were formed: A group of early professional musicians, a group of late-start professional musicians, and a non-musicians control group. The Battery of Attention and Memory (NEUROPSI) were applied individually. Results: Descriptively, we found that the performance profiles of the three groups behave dissimilarly, and significant differences were found in memory, attention, executive functions, and musical perception, especially among musicians who started before adolescence vs. non-musicians. Conclusions: Early musical practice has a favorable impact on tasks that involve attentional processes, executive functions, and memory, although the practice can be beneficial throughout life.
\end{abstract}

Keywords:

Attention, memory, executive functions, musical processing

\section{Resumen:}

El procesamiento musical se ha descrito como un modelo de plasticidad estructural y funcional en el que se modifican las áreas involucradas y las conexiones. Estos cambios dependen de varias variables, incluido el inicio del entrenamiento. El estudio de la música como fenómeno neuropsicológico se ha vuelto relevante porque proporciona información sobre posibles beneficios cognitivos. Objetivo: describir y comparar cómo la práctica musical afecta el funcionamiento cognitivo en músicos que comenzaron su formación a una edad temprana y tardía. Método: se formaron tres grupos: un grupo de músicos profesionales tempranos, un grupo de músicos profesionales de inicio tardío y un grupo de control no músicos. La Batería de Atención y Memoria (NEUROPSI) se aplicaron individualmente. Resultados: Descriptivamente, encontramos que los perfiles de desempeño de los tres grupos se comportan de manera diferente, y se encontraron diferencias significativas en la memoria, la atención, las funciones ejecutivas y la percepción musical, especialmente entre los músicos que comenzaron antes de la adolescencia frente a los no músicos. Conclusiones: la práctica musical temprana tiene un impacto favorable en tareas que involucran procesos atencionales, funciones ejecutivas y memoria, aunque la práctica puede ser beneficiosa durante toda la vida.

\section{Palabras Clave:}

Atención, memoria, funciones ejecutivas, procesamiento musical

a Facultad de Psicología, Universidad Nacional Autónoma de México, https://orcid.org/0000-0002-2577-0568, Email: arecellist@gmail.com

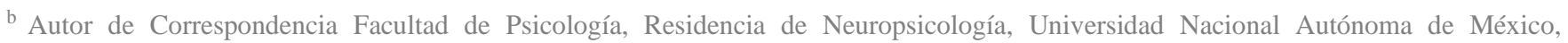
https://orcid.org/0000-0002-4978-1667, Email: gabrielaorocal@gmail.com

${ }^{c}$ Facultad de Psicología, Residencia de Neuropsicología, Universidad Nacional Autónoma de México, https://orcid.org/0000-0002-17332285 Email: maujaraf@yahoo.com.mx

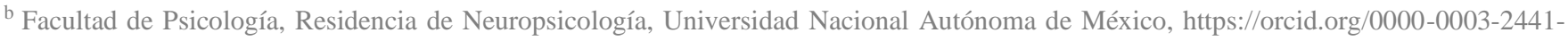




\section{INTRODUCTION}

Music plays a significant role in the life of the human being and is present in all cultures. When talking about complete musical processing, it refers to the input of musical information (melody), by a sensorial way commonly auditory or visual (as in the reading of scores), or by the interpretation of this information and the output (playing an instrument, evoking emotion). Music is considered a complex activity with high cognitive demand, which requires a modular system, where each module is responsible for processing essential elements and that through connections between them, a complete analysis can be made. An investigation has been made on how different brain areas and their connections are involved in each one (Peretz \& Coltheart, 2003).

Studies with musicians indicate that musical practice and perception lead to a state of cerebral plasticity where structures and laterality are modified, being able to reflect on functional changes and, therefore, non-musical cognitive processes can also be modified when performing this type of practices continuously. In the context of hemispheric specificity, it is necessary to separate the listener and the music professional. Although a listener perceives music in its total melodic contour, the professional listens to it as a relationship between elements and musical symbols, analyzing its structure (Afifi et al., 2005). It has been proposed that an innate approach to the musical phenomenon involves the right hemisphere (Kimura, 1964); that is, the perception of the melody itself (Koelsch, 2005). It has been shown that trained musicians use the left hemisphere more, which fulfills the function of an additional and individualized analyzer of each musical component and the relationship between them. However, there is also an undoubted implication of the right hemisphere for the global perception of music (Pozo et al., 2013). Thus, the study of music as a neuropsychological phenomenon has gained relevance, as it provides valuable information regarding a wide variety of cognitive processes. In general, musicians have better performance in verbal memory tasks (Chan, Ho, \& Cheung, 1998), sensorimotor integration, visual attention (Rodrigues, Loureiro \& Caramelli, 2014) working memory (Clayton Swaminathan, Yazdanbakhsh, Zuk, Patel, \& Kidd, 2016).

It is essential to consider the stage of neurodevelopment in which the musical practice begins for the evaluation of structural and functional changes. Like any development, the musical is a process of changes (Miranda, 2013) that although definite stages can be identified (Sloboda et al., 1985), it can also be considered as a continuum throughout life (Trainor, 2005). In any case, these changes involve the development of cognitive skills beyond the musical field, even in advanced stages of life. Correctly in music, early training (before age seven) influences structural development, especially in auditory cortex and motor cortex (Rosenkranz, Williamon, \& Rothwell, 2007; Hyde, Lerch, Norton, Forgeard, Winner, Evans, \& Schlaug , 2009) and have higher volume in the anterior portion of the corpus callosum (Penhune, 2011; Schlaug et al., 1995).

Musicians with early-onset, overcome motor tasks (Watanabe, Savion-Lemieux and Penhune et al., 2007), musical tasks of tone recognition (Penhune, 2011), and present differences in auditory evoked potentials (Koelsch, Fritz, Schulze, Alsop, \&
Schlaug, 2005; Martin, Tremblay, \& Stapells, 2007) when compared with musicians with musical training after this age. It has been described that the age of beginning of the musical practice influences functional changes in motor and auditory areas for musical processing. It has been observed that nonmusical cognitive functions such as language and memory have critical periods for their more significant development, it has not been described if the early onset of musical practice is related to the best development of these cognitive functions. The objective of this study was to describe the cognitive profile of professional musicians who began their training before adolescence, comparing it with the performance profile of musicians who began during or after adolescence and a group of non-musicians.

\section{METHOD}

Non-experimental, transversal design, with descriptive scope. Sampling for convenience.

Participants: A total of 45 people divided into three groups, musicians who started before adolescence (MA), group of musicians who started after adolescence (MD), and a group of people without musical experience (NM) were evaluated. For the MA group, male and female professional musicians were recruited who are currently exercising that profession and have started their training before adolescence, at least 10 years in the execution of their instrument. The MD group included professional musicians who started their training during or after adolescence and who were 10 years in the formal practice of the instrument. The control group (NM) was made up of men and women without musical studies. The members of the three groups had the same age and schooling range (age: 31 to 55 years and schooling from 10 to 24 years) according to the ranges established to obtain the execution profile of the Batería Neuropsicológica Atención y Memoria (Ostrosky et al. 2012).

Participants should not have a history of neurological or psychiatric conditions, as well as uncorrected hearing and vision problems. Regarding the laterality, the MA group had 2 left-handed and 13 right-handed people; the MD group was 1 left-handed, 1 ambidextrous and 13 right-handed, and of the NM group 1 left-handed and 14 right-handed. Informed consent for study participation was signed. They were evaluated in an office at the School of Psychology of the UNAM (National University of Mexico).

\section{Instruments}

Neuropsychological Battery Attention and Memory, NEUROPSI (Batería Neuropsicológica Atención y Memoria) developed by Ostrosky, Gómez, Ardila, Rosselli, Pineda and Matute 2nd ed. (2012) Instrument that includes 27 subtests that evaluate attention (orientation, selective, sustained attention and attention control), memory (short-term and longterm memory for verbal and visuospatial material), and executive functions (inhibition and working memory). The application of this test is individual and takes 50 to 60 minutes. The battery was validated and standardized for the Mexican population considering the age and schooling of the participant. A profile is obtained for each participant in which the scores of each task can be identified, as well as the total 
score obtaining a cognitive functioning from normal-high, normal, mild to moderate, and severe deterioration.

\section{Procedure}

Participants were recruited through a printed announcement placed in vocational schools (National Conservatory of Music, Higher School of Music, and School of Music) and professional orchestras based in Mexico City.

The control group was recruited in different places. All participants signed an informed consent where the procedure and the confidentiality of the information obtained were briefly explained. The battery application was performed individually in a single session with an approximate duration of one hour.

\section{STATISTIC ANALYSIS}

The statistical package SPSS version 21 was used. The data were processed to Shapiro-Wilk normality test, where the distribution of the data was associated with rejection in the normality hypothesis and with the Levene test for variance homoscedasticity where it was also rejected the null hypothesis, so an analysis was carried out using nonparametric statistics

For the statistical analysis, the Kruskal-Wallis test $(\mathrm{p}<0.05)$ was used, and for the post Hoc analysis, the Mann Whitney $\mathrm{U}$ with Bonferroni correction ( $\mathrm{p}<0.017$ ).

\section{RESULTS}

The analysis of sociodemographic variables indicated that the mean $(X)$ of age for the MA group was 39.26 with a standard deviation (SD.) of 8.56, in the MD group the age $X$ was 39.53 with a SD of 7.70 , and for the NM group, the $\bar{X}$ was 41.26 with a SD of 7.60. The groups did not show significant age differences $(\chi 2=0.88 ; \mathrm{p}=0.64)$.

In schooling significant differences were observed $\left(\chi^{2}=\right.$ $16.76 ; p=0.002)$, the MD group has more years of study NM $(\overline{\mathrm{X}}=21.86, \mathrm{SD}=4.38)$, than the $\mathrm{NM}$ group $(\mathrm{X}=17.26, \mathrm{SD}=$ $2.49)$, which was significant in the statistical analysis $(\mathrm{U}=$ $19.23, \mathrm{p}<0.002$ ).

Significant differences were found in the age of onset between the groups of musicians $(U=225 ; p=0.000)$, the average of the MA group was 7.73 and that of MD 15 years, without differences in the time and hours of practice. In the execution profile of NEUROPSI attention and memory, the level of execution in the normal-high range was higher in the MA group with a percentage of $73.33 \%$; and in the same range of normal-high in the MD group, the percentage was lower $46.66 \%$. The other participants were in a normal execution range.

Regarding the total NEUROPSI Attention and Memory battery scores, significant differences were found $(\mathrm{p}<.05)$, between the groups in the total attention and executive functions $(\chi 2=$ $20,90 / \mathrm{p}=0.000)$, the total of memory $(\chi 2=12,06 / \mathrm{p}=0.002)$ and for the global total $(\chi 2=16,20 / \mathrm{p}=0,000)$. When performing the post hoc test to see between which groups there were differences, in the total attention and executive functions the differences were found between the group MA and NM $(\mathrm{U}=20.00 / \mathrm{p}=, 000)$ and MD and NM $(\mathrm{U}=22.00 /$ $\mathrm{p}=.004)$. In the total memory, differences were found between the group MA and NM $(U=27.50 / p=0.002)$. In the overall total, differences were found between MA and NM (U $=23.50 / \mathrm{p}=0.000)$ and between $\mathrm{MD}$ and $\mathrm{NM}(\mathrm{U}=45.00$ $/ \mathrm{p}=0.031)$.

In all cases, the mean of the MA group was the highest. No significant differences were found between the two groups of musicians for any score. Regarding general cognitive functioning, on average, each of the groups has a normal performance range according to the normalized score of the performance profile, generally observing a better performance by the group of musicians who started their training before adolescence.

When analyzing battery subtests that evaluate memory, significant differences were found in regression cube subtests $(\chi 2=6.89 ; \mathrm{p}=0.03),(\mathrm{MA}: \mathrm{X}=6.00 ; \mathrm{SD}=1.13 ; \mathrm{NM}(\overline{\mathrm{X}}=$ 4.93, of $=, 79 ; \mathrm{U}=52.50 ; \mathrm{p}=0.01)$; In the sub-tests of information coding, differences were found in word list category formation $(\chi 2=6.40 ; \mathrm{p}=, 04),(\mathrm{MA}: \overline{\mathrm{X}}=4.06$, of $=$ 2.21; MD: $\mathrm{X}=2.20, \mathrm{SD}=1.89 ; \mathrm{U}=54.50 ; \mathrm{p}=0.001)$; word pairs $(\chi 2=7.28 ; \mathrm{p}=0.02), \mathrm{MA}: \mathrm{X}=9.86, \mathrm{SD}=1.18 ; \mathrm{NM}: \mathrm{X}$ $=7.73, \mathrm{SD}=2.34 ; \mathrm{U}=48.00 ; \mathrm{p}=0.007)$ and history $(\chi 2=$ $7.24, \mathrm{p}=0.02)$, (MA: $\mathrm{X}=10.66$, of $=1.49$; NM: $\mathrm{X}=8.73$, SD $=1.83 ; \mathrm{U}=47.50 ; \mathrm{p}=0.006$ ).

Regarding the evocation of the information, differences were found in word pairs $(\chi 2=7.91 / \mathrm{p}=0.01), \mathrm{MA}: \mathrm{X}=11.00, \mathrm{SD}$ $=1.13 ; \mathrm{NM}: \mathrm{X}=8.93, \mathrm{SD}=2.37 ; \mathrm{U}=51.50 ; \mathrm{p}=0.01)$; errors in word pairs $(\chi 2=10.00 ; \mathrm{p}=0.007),(\mathrm{NM}: \overline{\mathrm{X}}=, 86, \mathrm{SD}=, 91$; MA: $\bar{X}=0.06$, de $=0.25 ; \mathrm{U}=51.00 ; \mathrm{p}=0.01)$ and history $(\chi 2$ $=8.51 ; \mathrm{p}=0.01),(\mathrm{MA}: \mathrm{X}=10.53, \mathrm{SD}=1.68 ; \mathrm{NM}: \mathrm{X}=8.13$, of $=1.99 ; U=42.00 ; p=0.003)$. In the subtests of regression cubes, coding: formation of word categories, word pairs, history, evocation: word pairs and history, the average of the group that began their training before adolescence was higher than the other groups, followed by the group that started during or after adolescence, except for the formation of word categories where it was the lowest group. As for the errors in the evocation of word pairs, they were more in the group of non-musicians.

When analyzing the attention subtests and executive functions, significant differences were found in the subtests of cubes in progression $(\chi 2=6.40 ; \mathrm{p}=0.04)$, digit detection $(\chi 2=16.43$ / $\mathrm{p}=0.000),(\mathrm{MA}: \overline{\mathrm{X}}=9.93$, of $=, 25 ; \mathrm{NM}: \overline{\mathrm{X}}=8.66$, of $=1.34$; $\mathrm{U}=41.50 ; \mathrm{p}=0.000 ; \mathrm{MD}: \overline{\mathrm{X}}=9.80$, of $=0.56 ; \mathrm{NM} ; \mathrm{U}=$ $50.00 ; \mathrm{p}=0.009)$, intrusion in the detection of digits $\left(\chi^{2}=\right.$ 13.50; $\mathrm{p}=0.000)$, formation of categories $(\chi 2=30.15 ; \mathrm{p}=$ $0.000)$, (MA: $X=23.26$, of $=3.61 ; \mathrm{MD}: \overline{\mathrm{X}}=13.86$, of $=2.06$; $\mathrm{U}=2.50 ; \mathrm{p}=0.000 ; \mathrm{NM}: \overline{\mathrm{X}}=19.13$, of $=5.43 ; \mathrm{MD} ; \mathrm{U}=6.00$; $\mathrm{p}=0.000)$ and time in Stroop $(\chi 2=7.89 / \mathrm{p}=0.01),(\mathrm{NM}: \overline{\mathrm{X}}=$ 32.40 , of $=7.5 ; \mathrm{MD}: \overline{\mathrm{X}}=27.13$, of $=6.96 ; \mathrm{U}=51.50 ; \mathrm{p}=$ $0.01)$.

Cubes in progression, detection of digits and category formation, the group of musicians who began their training before adolescence, the averages were higher; followed by those that began during or after adolescence, except in training of categories, where the average of this group was lower than that of the non-musicians group. Regarding the number of intrusions in the detection of digits and the time in performing the Stroop subtest, the group of non-musicians had a higher average of intrusions and required more time to perform the task, compared to the groups of musicians. 


\section{DISCUSSIONS AND CONCLUSIONS}

According to the results obtained in this study, it can be said that musical practice has a favorable impact on tasks involved in attention processes, executive functions, and memory. The musical processing model of Peretz, et al. (2003) states that there are specific modules to interpret musical information (tone and rhythm processing), but these modules interact with other modules that are not restricted to this type of information (memory to identify tones besides words), and, when many brain areas and their connections are involved, practicing music can influence cognitive functioning in general.

A tendency was found in musicians who started at an early age to a position in high ranges according to the profile for their age and schooling, showing that they solved the tasks more effectively and that early training will be useful not only for musical performance but for cognitive functioning facing everyday stimuli. The results show significant differences in the total scores of attention and executive functions, and overall total between the group of musicians before adolescence and that of non-musicians. As well as between the group of musicians after adolescence vs. the group of nonmusicians; in terms of memory, the differences were only found among the group before adolescence vs. that of nonmusicians.

Dawn, Merret, and Wilson (2011) point out that activities that require constant practice and that involve different brain modules influence the structure and functioning of the brain, due to the phenomenon of the transfer. The effect of musical practice can be observed in both groups of musicians, observing that the control group obtained the lowest scores in most tasks.

The executive functions are the last in the developing process of the brain; they are still in development during adolescence, so musical practice can influence these functions. On the other hand, differences in total memory were not found between groups of musicians rather than the group before adolescence vs. non-musicians. And these can be explained because despite memory is a process that can be "exercised" throughout life, it is identified with brain areas that have matured before those that they are related to executive functions and are almost entirely mature in adolescence (Heyes, Zokaei, \& Husain, 2016), so the possibility of change may be less.

Significant differences were found between musicians before adolescence and non-musicians in the subtests cubes in progression and differences between the two groups of musicians vs. non-musicians in digit detection (number of digits and intrusions). In this regard, Mansens, Deeg, and Comijset (2017) found significant differences between musicians and non-musicians in a digit retention task in older adults; however, Giovagnoli and Raglio (2011), when using this same task, found no differences. In these studies, it can be seen that the age of beginning of the musical practice is not mentioned and that the number of years that the musicians have practiced (9 to 50 years), as well as their age (22 to 67 years), is very variable.

About the detection of digits that is an auditory modality in which the participants have to discriminate stimuli and focus their attention on those that are relevant to the task, it was observed that the group of musicians before adolescence had fewer intrusions and suggested that have developed strategies to identify relevant stimuli.
In this regard, Patston Hogg and Tippet (2007) used a task of detection in their visual modality finding shorter reaction times and more successes on the right side of the screen by the musicians. These results could be due to the fact that the musicians implement in their practice various types of attention. It is essential for them to sustain the attention during the rehearsal hours, they must be attentive to the different external stimuli, such as the signals of the orchestra director, the performance of their colleagues, the section of the score they are reading, as well as the sound of their instruments to feedback and effectively correct their possible errors. As shown, all these stimuli include different modalities such as auditory and visual, which also tend to be simultaneous in their practice. It was found that there were significant differences in the category training subtest and the time to perform the Stroop task. Working with adults and children, Zuk, Benjamin, Kenyon, and Gaabet (2014) used the tasks of Trail Making a test, verbal fluency, and the interference task of Stroop. They found that adult musicians compared to nonmusicians showed better performance in tasks of flexibility, verbal fluency, and inhibitory control, and the musically trained children showed significant differences with those not trained in verbal fluency and processing speed tasks. Although no significant differences in Stroop's task were found in the investigation, it could be seen that the group of musicians before adolescence required less time to perform the task, which indicates a higher processing speed.

In another study in which they evaluated inhibitory control, through the visual go-no go task and evoked potentials, in five-year-old children trained for more than four weeks, they concluded that there is a relationship between musical training and this executive function (Moreno \& Farzan, 2015), in addition to lower response latency. With the subtest of categories, a higher number of these were found in the musicians who began their training before adolescence Degé, Kubicek, and Schwarzeret (2011) found significant differences in category formation, clock test, Token test.

On the other hand, in this study, it was found that musicians who started late had much fewer categories than the group of non-musicians, which is a strange result because it would be expected that, even if they started late, they performed better or equal to non-musicians.

Clayton et al. (2016) relating a visual-auditory task (cocktail party effect) with executive functions such as flexibility, inhibition, and memory of auditory work and selective visual attention (multiple-object tracking), they found that musicians performed better in the cocktail effect and working memory. The study of Roden, Grube, Bongard, and Kreutz (2013) gave daily musical training for 45 minutes to children between 7 and 8 years old, applying computerized tasks on both visual and working memory, at different times of the training. They found that although the group of children who did not receive musical training had a higher score on the baseline, the group of children who received musical

training was significantly improving their performance in the following measurements.

Other authors who also used the tasks of regression digits in addition to ordering figures in a matrix for the version of visual stimuli were Suarez et al., (2015), they worked with adult musicians concluding that the practice is related to a better performance in working memory for both auditory and visual tasks. Their results agree with the present investigation 
since differences were also found in regression cubes, and although they were not found for digits, they were found in the alphabetical ordering task that corresponds to the verbalauditory modality.

It has been found that the results for auditory work memory such as digits have been inconsistent, for example, George and Coch (2011) found a positive relationship between musical practice and backward digits in young adults, but Bugos et al., (2007) found no differences in this when they evaluated older adults with musical training and a control group, Lee, Lu and Ko (2007) found a higher retention of regression digits in musically trained children but not in musically trained adults.

The reason that these results are inconsistent could be because of that the ages of the participants vary greatly. In one study, children have given music training for a few weeks. In another, young people and finally, older adults were evaluated. These studies show that age is an essential factor to observe a different performance in this type of task, so musical training improves executive functions at an early age (Steele, et al. 2013) and could help maintain these functions in adulthood.

In memory, significant differences were found in the coding phase in the subtests of category formation to remember the list of words, word pairs, and stories. In the evocation phase, significant differences were found in word pairs, number of errors when evoking them and stories, which were practically the same as in the coding phase, and it can also be noted that all these subtests belong to the auditory sensory modality.

In all subtests, the group of musicians before adolescence obtained the highest scores. But the differences were only between them and non-musicians, except for the categories to remember the list of words where there were differences between the groups of musicians. As it was addressed before, early-onset musicians have developed different strategies to be able to solve this type of tasks more effectively, and this is consistent with case studies of professional musicians who have suggested that experts developed "mind maps" of music during their practice that consist of crucial points of subjective importance in music. They use the expressive characteristics at these points (speed/loudness changes) that can be automatically retrieved and serve as a guide for their performance (Chaffin, Lisbon, Logan, \& Begosh, 2010).

These findings are comparable with a study where both musical stimuli and non-musical stimuli (ambient sounds and speech) and isolated objects and abstract art were used to study the auditory and visual memory of musicians. Significant differences were found between musicians and non-musicians, scoring better the musicians in tasks that included both musical and non-musical auditory stimuli; in terms of visual recognition, no significant differences were found (Cohen et al., 2014).

Other research found that auditory memory improves in musicians, but not visual memory (Chan, et al., 1998). While Rodrigues et al. (2014) report that in an image memorization task there were significant differences in reaction times, but not in accuracy, they suggest that there may be better sensorimotor integration by musicians. Giovagnoli and Raglio (2011), using the copy and memory of Rey's complex Figure and the word list learning task, did not find significant differences, this agrees with this research because no difference was found in these tasks more than in the strategy used to solve the word list.
At the beginning of the investigations of memory in music, Hughes (1915) mentioned that music could be memorized in three ways: by ear, reading notes, by sensory and motor memory, automatically moving the fingers over the instrument. These characteristics of musical memory share brain areas of memory for any other activity, so that musicians could perform better in these auditory and visual tasks according to more recent studies such as those already mentioned.

The majority of the musicians in the sample were of righthanded laterality, it has been described that hemispheric specialization for specific components of the musical processing and that these may have a correspondence with the non-musical cognitive processes, for example, of language (reading and prosody) and with verbal and visual memory (Pozo et al., 2013). However, it is not said that musical practice results in hemispheric specialization for cognitive functioning since the practice includes several components that involve both hemispheres depending on what is being done.

In sensory-motor areas, it has been described that by electrically stimulating the hands of musicians, there is a much stronger response in the fingers of the left hand, since it is the most frequently used hand when playing a string instrument (Jancke et al. 2000; Limb et al. 2006). While, in the general population, cognitive functioning (attention) without musical stimuli is usually higher in the right hemisphere (Portellano, 2013).

On the other hand, Patston et al. (2007) presented adult musicians with more than 8 years of practice stimuli on a screen divided by a middle line. They found that both musicians and the control group performed more accurately the task that involved stimuli on the left side, but the performance of musicians with the stimuli on the right side was significantly more precise than that of the control group, in addition, the reaction time was shorter, indicating a more "balanced" attention span in both hemispheres.

In conclusion, the differences in performance observed in the cognitive profiles of the groups show that musical practice is an activity that can influence the development of multiple cognitive functions, both visual and auditory. Lifelong learning is possible, so practicing music both early and late will be beneficial. However, it should be considered that there are critical periods that facilitate the adaptation of the developing brain to its environment and where significant and more lasting changes can be found.

\section{REFERENCES}

Bugos, J., Perlstein, W., McCrae, C., Brophy, T., \& Bedenbaugh, P. (2007). Individualized Piano Instruction enhances executive functioning and working memory in older adults. Aging \& Mental Health, 11(4), 464-471. doi: 10.1080/13607860601086504

Chaffin, R., Lisboa, T., Logan, T., \& Begosh, K. (2009). Preparing for memorized cello performance: the role of performance cues. Psychology of Music, 38(1), 3-30. doi: 10.1177/0305735608100377

Chan, A., Ho, Y., \& Cheung, M. (1998). Music training improves verbal memory. Nature, 396(6707), 128-128. doi: 10.1038/24075

Clayton, K., Swaminathan, J., Yazdanbakhsh, A., Zuk, J., Patel, A., \& Kidd, G. (2016). Executive Function, Visual Attention and the 
Cocktail Party Problem in Musicians and Non-Musicians. PLOS ONE, 11(7), 1-17. doi: 10.1371/journal.pone.0157638

Cohen, M., Evans, K., Horowitz, T., \& Wolfe, J. (2011). Auditory and visual memory in musicians and nonmusicians. Psychonomic Bulletin \& Review, 18(3), 586-591. doi: 10.3758/s13423-011-0074-0

Dawn, L., Merrett, D., \& Wilson, S. (2011). Auditory and visual memory in musicians and nonmusicians. In N. Rickard, Lifelong Engagement with Music: Benefits for Mental Health and Well-Being (1st ed., pp. 123-161). New York: Nova Science Publishers Inc.

Degé, F., Kubicek, C., \& Schwarzer, G. (2011). Music Lessons and Intelligence: A Relation Mediated by Executive Functions. Music Perception: An Interdisciplinary Journal,29(2), 195-201. doi: 10.1525/mp.2011.29.2.195

George, E., \& Coch, D. (2011). Music training and working memory: An ERP study. Neuropsychologia, 49(5), 1083-1094. doi: 10.1016/j.neuropsychologia.2011.02.001

Giovagnoli, A., \& Raglio, A. (2011). Cognitive Abilities of Musicians. Perceptual and Motor Skills, 113(2), 563-569. doi: 10.2466/04.11.22.23.pms.113.5.563-569.

Hughes, E. (1915). Musical memory in piano playing and piano study. The Musical Quarterly, 1(4), 592-603. doi: 10.1093/mq/i.4.592

Meister, I., Krings, T., Foltys, H., Boroojerdi, B., Müller, M., Töpper, R., $\&$ Thron, A. (2004). Playing piano in the mind-an fMRI study on music imagery and performance in pianists. Cognitive Brain Research, 19(3), 219-228. doi: 10.1016/j.cogbrainres.2003.12.005

Heyes, S., Zokaei, N., \& Husain, M. (2016). Longitudinal development of visual working memory precision in childhood and early adolescence. Cognitive Development, 39, 36-44. doi: 10.1016/j.cogdev.2016.03.004

Hyde, K., Lerch, J., Norton, A., Forgeard, M., Winner, E., Evans, A., \& Schlaug, G. (2009). Musical Training Shapes Structural Brain Development. Journal of Neuroscience, 29(10), 3019-3025. doi: 10.1523/jneurosci.5118-08.2009

Koelsch, S., Fritz, T., Schulze, K., Alsop, D., \& Schlaug, G. (2005). Adults and children processing music: An fMRI study. Neuroimage, 25(4), 1068-1076. doi: 10.1016/j.neuroimage.2004.12.050

Lee, Y., Lu, M., \& Ko, H. (2007). Effects of skill training on working memory capacity. Learning and Instruction, 17(3), 336-344. doi: 10.1016/j.learninstruc.2007.02.010

Mansens, D., Deeg, D., \& Comijs, H. (2017). The association between singing and/or playing a musical instrument and cognitive functions in older adults. Aging \& Mental Health, 22(8), 970-977. doi: $10.1080 / 13607863.2017 .1328481$

Martin, B., Tremblay, K., \& Stapells, D. (2007). Principles and applications of cortical auditory evoked potentials. In R. F. Burkard, M. Don \& J. J. Eggermont (Eds.), Auditory Evoked Potentials: Basic Principles and Clinical Applications (pp. 482-507).

Miranda, L.D. (2013). Psicología y música: elaboración de perfiles de desarrollo integral en alumnos de la Escuela Nacional de Música. (Degree Thesis). Universidad Nacional Autónoma de México. México

Moreno, S., \& Farzan, F. (2015). Music training and inhibitory control: a multidimensional model. Annals of The New York Academy of Sciences, 1337(1), 147-152. doi: 10.1111/nyas.12674

Ostrosky, F., Gómez, E., Ardila, A., Roselli, M., Pineda, D., \& Matute, E. (2012). NEUROPSI: Atención y Memoria (1st ed.). Ciudad de México: El Manual Moderno.

Patston, L., Hogg, S., \& Tippett, L. (2007). Attention in musicians is more bilateral than in non-musicians. Laterality: Asymmetries of Body, Brain and Cognition, 12(3), 262-272. doi: $10.1080 / 13576500701251981$
Penhune, V. (2011). Sensitive periods in human development: Evidence from musical training. Cortex, 47(9), 1126-1137. doi: 10.1016/j.cortex.2011.05.010

Peretz, I., \& Coltheart, M. (2003). Modularity of music processing. Nature Neuroscience, 6(7), 688-691. doi: 10.1038/nn1083

Roden, I., Grube, D., Bongard, S., \& Kreutz, G. (2013). Does music training enhance working memory performance? Findings from a quasi-experimental longitudinal study. Psychology of Music, 42(2), 284-298. doi: 10.1177/0305735612471239

Rodrigues, A., Loureiro, M., \& Caramelli, P. (2014). Visual memory in musicians and non-musicians. Frontiers in Human Neuroscience, 8. doi: 10.3389/fnhum.2014.00424

Rosenkranz, K., Williamon, A., \& Rothwell, J. (2007). Motorcortical Excitability and Synaptic Plasticity Is Enhanced in Professional Musicians. Journal of Neuroscience, 27(19), 5200-5206. doi: 10.1523/jneurosci.0836-07.2007

Schlaug, G. (1995). Increased corpus callosum size in musicians. Neuropsychologia, 33(8), 1047-1055. doi: 10.1016/00283932(95)00045-5

Sloboda, J. (1985). The musical mind: The cognitive Psychology of music (1st ed.). Oxford: Oxford University Press.

Suárez, L., Elangovan, S., \& Au, A. (2015). Cross-sectional study on the relationship between music training and working memory in adults. Australian Journal of Psychology,68(1), 38-46. doi: 10.1111/ajpy. 12087

Patston, L., Hogg, S., \& Tippett, L. (2007). Attention in musicians is more bilateral than in non-musicians. Laterality: Asymmetries Of Body, Brain And Cognition, 12(3), 262-272. doi: 10.1080/13576500701251981

Trainor, L. (2005). Are there critical periods for musical development? Developmental Psychobiology,46(3), 262-278. doi: $10.1002 / \mathrm{dev} .20059$

Watanabe, D., Savion-Lemieux, T., \& Penhune, V. B. (2007). The effect of early musical training on adult motor performance: evidence for a sensitive period in motor learning. Experimental Brain Research, 176, 332-340. doi: 10.1007/s00221-006- 0619-z. 